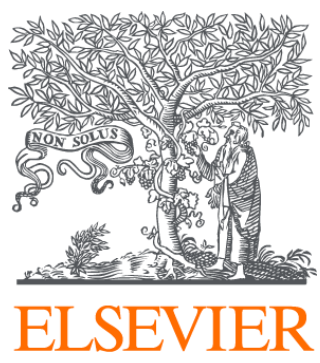

Since January 2020 Elsevier has created a COVID-19 resource centre with free information in English and Mandarin on the novel coronavirus COVID-

19. The COVID-19 resource centre is hosted on Elsevier Connect, the company's public news and information website.

Elsevier hereby grants permission to make all its COVID-19-related research that is available on the COVID-19 resource centre - including this research content - immediately available in PubMed Central and other publicly funded repositories, such as the WHO COVID database with rights for unrestricted research re-use and analyses in any form or by any means with acknowledgement of the original source. These permissions are granted for free by Elsevier for as long as the COVID-19 resource centre remains active. 


\title{
Treatment and prevention of necrotizing enterocolitis
}

\author{
Jane S. Lee, Richard A. Polin* \\ Columbia University, College of Physicians and Surgeons, Children's Hospital of New York-Presbyterian, \\ CHS 115, 3959 Broadway, New York, NY 10032, USA
}

Received 1 June 2003; accepted 1 July 2003

\section{KEYWORDS}

Necrotizing

enterocolitis;

Probiotics;

Inflammation;

Feeding practices;

Bacterial translocation

\begin{abstract}
Summary Necrotizing enterocolitis (NEC) is the most common serious, acquired gastrointestinal disorder in the newborn infant. Although many variables are associated with development of NEC, only prematurity has been consistently identified in case-controlled studies. Traditionally, the diving seal reflex has been invoked as the mechanism responsible for ischaemic injury and necrosis. Intestinal ischaemia is likely to be the final common pathway in NEC; however, it is due to the release of vasoconstricting substances, such as platelet activating factor, rather than perinatal asphyxia. Bacteria and/or bacterial toxins are likely to have a key role in the pathogenesis of NEC by fostering production of inflammatory mediators. The role of feeding practices in the pathogenesis of NEC remains controversial. Treatment of infants with NEC generally includes a regimen of bowel rest, gastric decompression, systemic antibiotics and parenteral nutrition. Infants with perforation are generally operated upon; however, there has been recent interest in primary peritoneal drainage as an alternative. Prevention of NEC still remains elusive. Avoidance of preterm birth, use of antenatal steroids and breast-milk feeding are practices that offer the greatest potential benefits. Use of any other strategy should await further trials.

(c) 2003 Elsevier Ltd. All rights reserved.
\end{abstract}

\section{Introduction}

Necrotizing enterocolitis (NEC) is the most common serious, acquired gastrointestinal disease in the newborn infant, affecting $1-3 \%$ of neonatal intensive care unit (NICU) admissions. ${ }^{1}$ The National Center for Health Statistics and multicentre trials have estimated that there are between 1200 and 9600 cases per year in the USA, resulting in up to 2688 deaths. The term 'necrotizing enterocolitis' first appeared in the European literature in the early 1950s in articles by Schmid and Quaiser who described infants dying from necrotic lesions of the gastrointestinal tract. ${ }^{2}$ However, it was not until

\footnotetext{
* Corresponding author. Tel.: +1-212-305-5827; fax: +1-212305-7086

E-mail address: rap32@columbia.edu (R.A. Polin).
}

the 1960s, when Santulli et al. reported a series of preterm infants with NEC at Babies Hospital, that it became recognized as a distinct clinical entity. ${ }^{3}$ Infants with NEC represent some of the sickest infants in the NICU, and exhibit a mortality rate ranging from $20-50 \%$. Furthermore, once an infant is definitively diagnosed with NEC, with the exception of supportive care, there is little one can do to alter the course of the disease. The incidence of NEC may be increasing as more infants weighing less than $1000 \mathrm{~g}$ survive. This population of infants is most susceptible to NEC, is more likely to require surgery, and has a greater probability of dying from the disease.

The original report of Santulli et al. described preterm infants who were critically ill. They often had low Apgar scores and commonly required 
placement of an umbilical arterial catheter for managing respiratory distress syndrome (RDS). Following the institution of formula feeding, affected infants developed abdominal distention and bloody stools. Abdominal radiographs demonstrated the cardinal sign of NEC (pneumatosis intestinalis), and in some cases, there was rapid progression to perforation. Based on clinical observations in infants and studies in experimental animals, three factors were felt to be necessary for NEC to occur: (1) mucosal injury (from asphyxia or catheters); (2) formula feeding (providing a substrate for bacterial fermentation); and (3) the presence of bacteria. The lack of improvement in the mortality rate for NEC over the past 10 years has prompted investigators to re-examine these epidemiologic factors, and search for strategies to prevent the disease. This article will review controversial concepts in the epidemiology and pathogenesis of NEC, and recent clinical trials designed to prevent NEC.

\section{Epidemiology}

As a result of the many advances in neonatal intensive care, NEC has emerged as a disease of NICU survivors. The overall incidence is $1-3$ cases per 1000 live births, with considerable variation observed among institutions and even within an institution. Although $5-25 \%$ of cases have been reported in full-term infants, it is a disease predominantly affecting premature infants. The incidence varies inversely with birthweight and gestational age..$^{4,5}$ Those most susceptible appear to be infants weighing less than $1000 \mathrm{~g}$ at birth and under 28 weeks' gestation. ${ }^{6,7}$ Data from the National Institute of Child Health and Human Development Neonatal Network (NICHD Neonatal Network) and the Vermont-Oxford Trials Network confirm this increased incidence among very-low-birthweight (VLBW) infants. ${ }^{8,9}$ The risk of NEC persists until a postconceptual age of at least 36 weeks is reached.

The majority of NEC cases are endemic; however, epidemics may also occur. No seasonal pattern has been reported. In most studies, male and female infants are equally affected. Age at onset is also inversely related to gestational age. In fullterm infants, NEC appears to occur at a median age of two days with greater than $40 \%$ presenting on the first day of life. ${ }^{5}$ Immature infants continue to be at prolonged risk for NEC; those born at 30 weeks' gestation or younger may not be symptomatic for several weeks. ${ }^{5}$

Once NEC has been diagnosed, the clinical presentation appears to be relatively similar among affected infants. The modified Bell staging system for NEC is shown in Table $1{ }^{10}$ Although the most common presentation is abdominal distention, other reported signs include feeding intolerance, haematochezia, lethargy, apnoea, respiratory failure and circulatory instability. ${ }^{11}$ Affected infants also exhibit, to varying degrees, laboratory abnormalities such as leukopenia or leukocytosis, anaemia, thrombocytopenia, hypo- or hyperglycaemia, electrolyte abnormalities and metabolic acidosis. Bacteraemia has been documented in up to $35 \%$ of cases. Although no single pathogen has been consistently identified, Escherichia coli, Klebsiella, Enterobacter, Pseudomonas, Salmonella, Clostridium perfringes, $C$. difficile, $C$. butyricum, coagulase-negative staphylococci, Enterococcus, coronavirus, rotavirus and enterovirus have been associated with NEC. ${ }^{12}$ The type of organism recovered varies with disease severity. In modified Bell stages I and II NEC, Gram-positive organisms appear to be the predominant pathogens recovered. As NEC worsens, enteric organisms are more commonly isolated. ${ }^{13}$ Radiographically, $70-80 \%$ of affected infants display signs of pneumatosis intestinalis, the accumulation of gas produced by gasforming bacteria in the submucosa or subserosa. ${ }^{14}$ Other signs of intestinal gangrene or impending perforation are portal venous gas (PVG), a fixed distended bowel loop, free intraperitoneal fluid or pneumoperitoneum. PVG is believed to represent either a dissection of gas from the bowel into portal veins or transfer to the portal system via the mesenteric veins; its prognostic importance is controversial. ${ }^{15}$ Ultrasonography has been proposed as a useful adjunct for identification of pneumatosis intestinalis, free intraperitoneal fluid and PVG.

Approximately $27-63 \%$ of affected infants require surgical intervention. The majority of postoperative complications are related to the stoma or wound. Strictures, found primarily in the colon, may occur in up to $39 \%$ of infected infants. ${ }^{14}$ NEC has been reported to recur in up to $6 \%$ of infants; however, no consistent association has been shown between recurrence and feeding regimen, anatomical site of injury, or management of initial disease. ${ }^{16}$ Total parenteral nutrition (TPN)-related complications may also occur. Infants with NEC also have extended hospitalizations (22 days in medical NEC and 60 days in surgical NEC beyond their healthy matched controls). ${ }^{17}$ Although VLBW infants with severe disease may be at higher risk of adverse outcomes, ${ }^{18,19}$ neurodevelopmental outcome measured at school age appears favourable in most infants. ${ }^{20}$ 
Table 1 Modified Bell staging criteria for necrotizing enterocolitis

\begin{tabular}{|c|c|c|c|c|}
\hline Stage & Classification & System signs & Intestinal signs & Radiological signs \\
\hline IA & Suspected NEC & $\begin{array}{l}\text { Temperature instability, apnoea, bradycardia, } \\
\text { lethargy }\end{array}$ & $\begin{array}{l}\text { Increased pregavage residuals, mild abdominal } \\
\text { distention, emesis, guaiac-positive stool }\end{array}$ & Normal or intestinal dilation, mild ileus \\
\hline IB & Suspected NEC & Same as above & Bright-red blood from rectum & Same as above \\
\hline IIA & Proven NEC-mildly ill & Same as above & $\begin{array}{l}\text { Same as above, plus absent bowel sounds, with } \\
\text { or without abdominal tenderness }\end{array}$ & $\begin{array}{l}\text { Intestinal dilation, ileus, pneumatosis } \\
\text { intestinalis }\end{array}$ \\
\hline IIB & Proven NEC-moderately ill & $\begin{array}{l}\text { Same as above, plus mild metabolic acidosis } \\
\text { and mild thrombocytopenia }\end{array}$ & $\begin{array}{l}\text { Same as above, plus absent bowel sounds, } \\
\text { definite abdominal tenderness, with or without } \\
\text { abdominal cellulitis or right lower quadrant } \\
\text { mass }\end{array}$ & $\begin{array}{l}\text { Same as IIA, plus portal vein gas, with } \\
\text { or without ascites }\end{array}$ \\
\hline IIIA & $\begin{array}{l}\text { Advanced NEC-severely ill, } \\
\text { bowel intact }\end{array}$ & $\begin{array}{l}\text { Same as IIB, plus hypotension bradycardia, } \\
\text { severe apnoea, combined respiratory and } \\
\text { metabolic acidosis, disseminated intravascular } \\
\text { coagulation, and neutropenia }\end{array}$ & $\begin{array}{l}\text { Same as above, plus signs of generalized } \\
\text { peritonitis, marked tenderness, and distention } \\
\text { of abdomen }\end{array}$ & Same as IIB, plus definite ascites \\
\hline IIIB & $\begin{array}{l}\text { Advanced NEC-severely ill, } \\
\text { bowel perforated }\end{array}$ & Same as IIIA & Same as IIIA & Same as IIB, plus pneumoperitoneum \\
\hline
\end{tabular}




\section{Pathogenesis of necrotizing enterocolitis}

Although NEC is an important cause of neonatal morbidity and mortality, its pathogenesis remains incompletely understood. Available theories do not explain the spectrum of observed manifestations of the disease satisfactorily. NEC most likely represents a complex interaction of factors predisposing to mucosal injury and the infant's subsequent response. $^{1}$

Intestinal ischaemia clearly occurs in NEC as evidenced by the histopathologic presence of inflammatory cell infiltration, mucosal oedema, ulceration and coagulative necrosis. ${ }^{21}$ However, it is unclear whether ischaemia is the primary initiator or the end result of intestinal injury. Early observational studies reported a significant association between numerous ischaemic events and the development of NEC. Factors often cited as possible risk factors were perinatal asphyxia, umbilical arterial catheterization, polycythaemia, exchange transfusion, RDS and cyanotic congenital heart disease. ${ }^{4}$ Medications such as indomethacin and methylxanthines, which have been shown to decrease superior mesenteric blood flow, have also been implicated. Many of these perinatal insults were believed to induce the 'diving seal reflex' by which blood flow is selectively shunted away from nonvital organs such as the intestine. ${ }^{22,23}$ However, this physiological mechanism does not fully explain what is seen clinically. Many infants with NEC have no history of perinatal depression at birth, and do not present with signs of NEC until several weeks of life. Recent epidemiologic studies also fail to confirm an association between these hypoxic factors and the development of NEC. ${ }^{4}$ The conflicting data suggest that ischaemia may be a secondary event reflecting a culmination of the various factors described below.

Prematurity is the only factor consistently found in epidemiologic studies to be an independent determinant of NEC. The increased susceptibility is attributed to an immature mucosal barrier and barrier response. ${ }^{1}$ In the presence of low intraluminal gastric acid and proteolytic activity, the incompletely innervated, poorly organized, relatively permeable epithelial barrier is vulnerable to bacterial colonization and pathogenic overgrowth. ${ }^{1,24,25}$ In premature infants, the humoral and cellular response to this overgrowth is impaired. Specifically, secretory IgA deficiency in the lymph-follicle-rich terminal ileum and colon facilitates bacterial translocation, while inadequate T-lymphocyte activity compromises recognition of ensuing membrane alterations. ${ }^{1,24}$
Enteral feedings have been implicated as a significant contributor in the development of NEC. Although NEC can occur in infants who have never been fed, $90-95 \%$ of cases occur in infants with a history of recent volume advancement or reinitiation of enteral feedings. ${ }^{5}$ The introduction of feedings into the intestinal lumen presumably causes a disruption of mucosal integrity, blood flow and motility. A substantially higher incidence of NEC has been reported in formula-fed infants compared with exclusively breast-fed infants, which has been attributed to a lack of immunoprotective factors. ${ }^{26}$ The timing, initial volume and advancement of feedings are important factors in determining the degree of the mucosal insult that occurs. Since much of the research performed in this area is conflicting, no consensus has been reached regarding the most effective feeding regimen.

The well-documented epidemics of NEC and the improvement in attack rate following the implementation of strict infection control measures validate the role of infection in the pathogenesis of NEC. The role of bacteria is two-fold. Fermentation of carbohydrate substrates by bacteria leads to formation of hydrogen gas (the gas found in pneumatosis intestinalis). Furthermore, as mucosal integrity is compromised, bacteria 'translocate' to regional lymph nodes and activate resident macrophages. Colonization of the intestine with bacterial species must precede bacterial translocation. ${ }^{24}$ The physiological growth of intestinal microflora and the pathological modifications of this microflora have been assessed through fecal bacterial measurements. Organisms are introduced into the sterile fetal intestine by contact with maternal vaginal flora. Species such as $E$. coli, streptococci and Bacteroides are commonly isolated during the immediate neonatal period. ${ }^{24}$ Colonization with aerobic and anaerobic flora normally occurs by 10 days of age. ${ }^{23}$ Over the first few weeks to months, the relative concentrations of $E$. coli and streptococci decline as the concentrations of lactobacilli and Bacteroides rise. ${ }^{24}$ Introduction of enteral feedings alters this pattern of intestinal colonization. Formula is associated with an early appearance of Enterobacteriaceae such as E. coli and Klebsiella, whereas breast feeding induces an early appearance of Enterobacteriaceae and Bifidobacterium. ${ }^{24,27}$ Regardless of the choice of feeding, bifidobacteria gradually become the dominant bacteria. In infants requiring neonatal intensive care, colonization occurs more slowly. Following the initiation of feedings in these infants, only a few species are present. If the hospitalization remains uncomplicated, enteric 
colonization continues to diversify. However, colonization is often delayed or reversed by interruptions in the feeding regimen or by the administration of broad-spectrum antibiotics. ${ }^{23,24,28}$ Clinically, delays in colonization appear to roughly correspond to the delay in disease presentation. Substantial alterations in the intestinal flora enable the bacterial overgrowth of a few organisms as a result of the lack of competition. The role of bacterial toxins is less clear. Lawrence et al. hypothesized that bacterial toxin absorption during periods of bacterial overgrowth was the primary mechanism for intestinal damage. ${ }^{23,29}$ However, the isolation of potent toxins, such as Clostridium toxin, in asymptomatic infants raises questions about the importance of toxin-mediated injury in the evolution of NEC. ${ }^{1,30}$

Once bacterial translocation or toxin absorption has occurred, the endogenous production of inflammatory mediators is likely to be a key step in the pathogenesis of NEC. From animal studies, it has been demonstrated that increases in tumour necrosis factor (TNF) and platelet activating factor (PAF) propagate the ongoing injury to the intestinal mucosa, which triggers a cascade of inflammatory events. ${ }^{27,31}$ This inflammatory response, consisting of leukocyte adhesion and activation, complement activation, and the release of cytokines, reactive oxygen species and nitric oxide, results in areas of focal necrosis. ${ }^{31}$ Clinically, elevated PAF and TNF levels, and reduced levels of PAF acetylhydrolase (the enzyme which degrades PAF) have been observed in infants with NEC. An imbalance of proand counter-inflammatory cytokines may partially explain the varying severity of the disease. ${ }^{32,33}$ In immature enterocytes, this injury may stimulate excessive pro-inflammatory cytokine production. ${ }^{34}$ However, attempts to correlate cytokine levels with the development and progression of NEC have generally been unsuccessful.

\section{Treatment of necrotizing enterocolitis}

Following the clinical diagnosis of NEC, the mainstay of treatment remains medical stabilization. A regimen consisting of bowel rest, gastric decompression, systemic antibiotics and parenteral nutrition is typically implemented. Initial broadspectrum antibiotic coverage at our institution consists of ampicillin, gentamicin and clindamycin. With the increasing prevalence of infections from coagulase-negative staphylococcus, vancomycin may be used instead of ampicillin. Amikacin and metronidazole have been substituted for gentamicin and clindamycin by others. ${ }^{11}$ However, antimicrobial choices should be guided by local resistance patterns. Enteral antibiotics are not recommended. Prompt correction of electrolyte abnormalities, persistent metabolic acidosis and coagulopathy are also recommended.

In cases where persistent clinical deterioration or signs of impending perforation or intestinal gangrene are present, operative intervention may be considered. In the absence of pneumoperitoneum, abdominal paracentesis may be helpful in confirming the presence of intestinal gangrene when used in conjunction with other available data. ${ }^{14}$ Currently, intestinal perforation remains the only absolute indication for laparotomy. The cardinal principle of surgical management is excision of grossly necrotic segments and exteriorization of viable ends to allow for continued bowel decompression. ${ }^{14}$ Recently, primary peritoneal drainage (PPD) has been proposed as an alternative to surgical treatment. Ein et al. first described the use of PPD for perforated NEC in VLBW infants in 1977; however, its use was limited to unstable VLBW infants. ${ }^{35}$ Although initially implemented as a temporizing measure, multiple published reports documented the successful use of PPD as adjunctive therapy prior to planned laparotomy (LAP) or as definitive therapy, particularly in extremelylow-birthweight infants less than $1000 \mathrm{~g}^{36-39} \mathrm{~A}$ meta-analysis by Moss et al. also demonstrated comparable combined probability of survival for infants with perforated NEC who were treated with either procedure $(67 \%$ in the LAP group vs $55 \%$ in the PPD group, $P=0.27$ ) even in the presence of a significant treatment assignment bias favouring the LAP group..$^{40}$ NEC STEPS, a prospective multicentre randomized controlled trial, is currently under way to examine the effectiveness of PPD vs LAP as primary therapy for perforated NEC in VLBW infants stratified by birthweight ( $<1000$ and $1000-1500 \mathrm{~g})$. A potential extension of the use of peritoneal drains in NEC is Moore's 'patch, drain, and wait' laparotomy approach, which consists of limited patching of major perforations, gastrostomy tube drainage, bilateral peritoneal drains, and longterm parenteral nutrition. ${ }^{14,41}$ In cases of isolated or multifocal NEC, some investigators advocate resection and primary anastomosis. When massive pneumatosis intestinalis without definite intestinal gangrene is present, proximal diversion via a high jejunostomy is recommended to minimize bacterial proliferation. ${ }^{14}$ Contrast enemas are typically performed prior to re-initiation of feedings in infants with perforated NEC or when feeding intolerance develops in infants with medical NEC. ${ }^{12}$ Approximately one-quarter of affected infants may 
Table 2 Strategies to prevent necrotizing enterocolitis: probable or proven efficacy

- Breast feeding

- Antenatal steroids

- Fluid restriction

- Enteral administration of antibiotics ${ }^{\mathrm{a}}$

${ }^{a}$ Potential for development of resistant flora.

Table 3 Strategies to prevent necrotizing enterocolitis: unproven efficacy or limited data

- Cautious advancement of feedings ${ }^{\mathrm{a}}$

- Trophic feeding ${ }^{a}$

- Enteral administration of immunoglobulin ${ }^{\mathrm{b}}$

- Supplemental l-arginine ${ }^{c}$

- Supplementation of feedings with egg phospholipids ${ }^{c}$

- Acidification of milk feedings ${ }^{c}$

- Administration of probiotics ${ }^{\mathrm{C}}$

a Unproven efficacy.

b Not efficacious.

'Limited data.

develop short gut syndrome. ${ }^{42}$ Some success with intestinal transplantation has been reported in this subset. Although experience is limited, the overall reported one- and three-year survival rates are 60 and $54 \%$, respectively. ${ }^{43}$

\section{Prevention of necrotizing enterocolitis}

Strategies for prevention of NEC fall into two major categories: those with probable or proven efficacy (Table 2), and those with unproven efficacy or based upon limited data (Table 3). When interpreting these studies, it is important to focus on both the overall incidence of NEC in the intervention and control groups, as well as the incidence of each stage. For example, an intervention that decreases the incidence of stage I disease (suspect NEC) is not as relevant as interventions that decrease the incidence of stage II or III disease. Not surprisingly, many of the suggested interventions have been directed at modifying feeding practices, since more than $95 \%$ of infants with NEC received milk feedings prior to the onset of the disease. For many years, breast milk has been advocated as a way to prevent NEC. ${ }^{12}$ More than 30 years ago, Barlow et al. demonstrated that breast milk was protective in a rodent model of NEC. ${ }^{44}$ Not surprisingly, that observation engendered a lot of enthusiasm for the use of breast milk to prevent NEC. Unfortunately, the expectation that breast milk would be protective has not been fulfilled. NEC does occur in infants who have been fed exclusively with human milk, especially milk that has been refrigerated, frozen or pasteurized. ${ }^{45}$ Some investigators have suggested that the severity of NEC is less in infants who have been fed human milk. Recent studies by Dvorak et al. lend support to this observation. ${ }^{46}$ Using a rat model of NEC, the investigators demonstrated that rat breast milk reduced the incidence and severity of NEC. It is noteworthy that freezing and thawing did not eliminate the protective effect of maternal milk. In this study, the protective effect of rat breast milk was associated with increased production of the anti-inflammatory cytokine IL-10 at the site of injury. Fresh human milk, however, contains numerous immunoprotective substances (immunoglobulins, lysozyme, lactoferrin, macrophages, lymphocytes and neutrophils) and bioactive factors (Table 4). ${ }^{47}$ In addition, human milk contains PAF acetylhydrolase, an enzyme that destroys PAF. ${ }^{48}$ PAF is one of the mediators thought to be important in the pathogenesis of NEC. ${ }^{49}$ Fresh milk also promotes colonization with Lactobacillus bifidus, which may also offer protection (see below). McGuire and Anthony recently published a systematic review of studies comparing donor human milk with formula for preventing NEC in preterm infants (Fig. 1). ${ }^{50}$ Eleven trials that appeared to be relevant were screened, and four of them fulfilled the inclusion criteria. Although none of the trials showed a statistically significant reduction in the incidence of confirmed NEC, the metaanalysis demonstrated a borderline, statistically

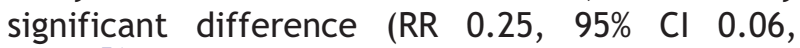
0.98). ${ }^{51}$ It is important to note that the studies chosen for inclusion were conducted more than 20 years ago, and may not be representative of current NICU practices or populations. There are insufficient data to show that use of preterm human milk (vs preterm formula) reduces the incidence of NEC.

In 1988, Eibl et al. published the results of a randomized clinical trial demonstrating a reduction in the incidence of NEC in preterm infants fed an oral IgA-IgG preparation. ${ }^{52}$ That report was followed by several other studies investigating whether oral immunoglobulin preparations resulted in a reduction in the incidence of the disease. Foster and Cole recently published a meta-analysis of studies employing that strategy. ${ }^{53}$ Five studies on oral immunoglobulin for prevention of NEC were reviewed and three of them met the inclusion criteria for the meta-analysis. The reviewers concluded that the evidence does not support the administration of oral immunoglobulin for 
Table 4 Potential effects of selected agents in human milk $(\mathrm{HM})$ on the gastrointestinal tract

\begin{tabular}{llll}
\hline Agent in HM & Epithelial growth & Decreased inflammation & sigA production \\
\hline EGF & + & $?$ & - \\
IGF-1 & + & $?$ & - \\
TGF & + & - & - \\
Erythropoietin & + & $?$ & - \\
IL-6 & - & $?$ & + \\
TNF- $\alpha$ & - & - & + \\
IL-10 & - & + & + \\
PAF-AH & - & + & - \\
Lysozyme & - & + &
\end{tabular}

GI, gastrointestinal; sigA, secretory immunoglobulin A; EGF, epithelial growth factor; IGF-1, insulin-like growth factor 1; TGF, transforming growth factor; IL, interleukin; TNF- $\alpha$, tumour necrosis factor $\alpha$; PAF-AH, platelet activating factor acetylhydrolase. Reproduced from Ref. 47, with permission.

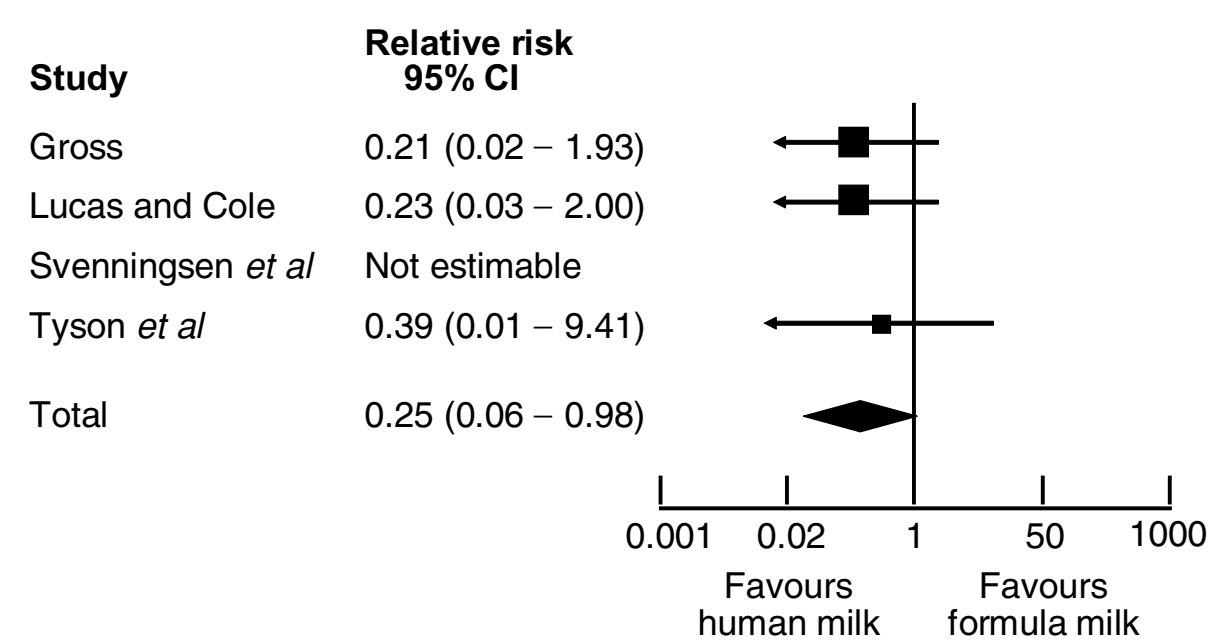

Fig. 1 Relative risk of confirmed necrotizing enterocolitis in infants randomized to donor human milk vs formula milk. Reproduced from Ref. 50, with permission.

prevention of NEC (RR for definite NEC $0.84,95 \% \mathrm{Cl}$ $0.57,1.25)$. In contrast, a meta-analysis of studies comparing restricted vs liberal water intake in preterm infants (Fig. 2) concluded that restricted water intake (without allowing significant dehydration) reduced the incidence of NEC (RR $0.30, \mathrm{Cl}$ $0.13,0.71) .{ }^{54}$ Similarly, a recent meta-analysis of prophylactic enteral antibiotics to prevent NEC (Fig. 3 and 4) demonstrated a significant reduction in the incidence of the disease (RR $0.27,95 \% \mathrm{Cl}$ $0.28,0.78$ ) and NEC-related deaths (RR $0.32,95 \% \mathrm{Cl}$ $0.10,0.96) .{ }^{55}$ However, because of the potential risk of development of resistant bacteria, that strategy should not be adopted until a large trial investigating all possible harmful effects has been completed.

There have been recent recommendations to limit increments in feeding volumes to decrease the likelihood of developing NEC. Those recommendations were based on retrospective data, which demonstrated a relationship between the rate of feeding advancement and an increased incidence of NEC. ${ }^{13,56}$ Prospective randomized trials have not reached similar conclusions. ${ }^{13,57-59}$ Berseth et al. compared a traditional enteral feeding protocol (using modest feeding advancements of $20 \mathrm{ml} / \mathrm{kg}$ / day) with a minimal enteral feeding protocol that was not advanced for 10 days. ${ }^{60}$ The study was terminated after 144 infants were randomized because of a significantly higher incidence of NEC in the feeding advancement group. While feeding advancement may have contributed to an increased incidence of NEC, there is also the possibility that minimal enteral feedings help protect against NEC, and this further supports the use of trophic feedings in critically ill preterm infants.

Probiotics (anaerobic bacterial supplementation with organisms such as bifidobacteria or lactobacilli) have been used for many years to treat a variety of gastrointestinal diseases. ${ }^{61}$ 


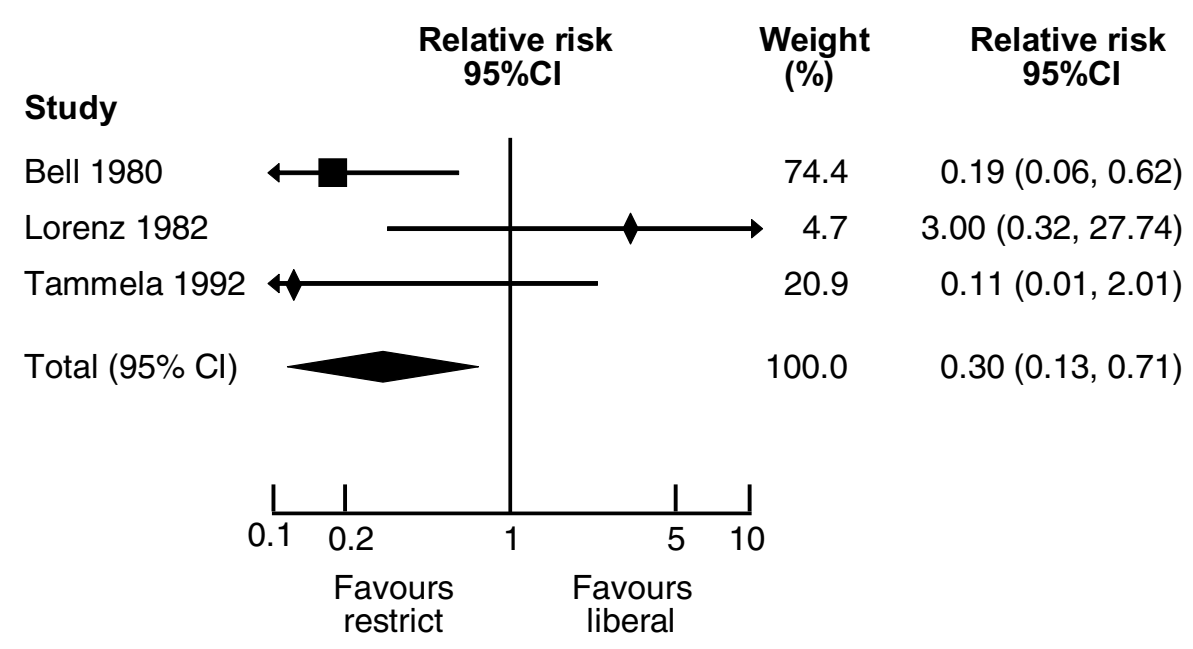

Fig. 2 Restricted vs liberal water intake for preventing necrotizing enterocolitis. Modified from Ref. 54.

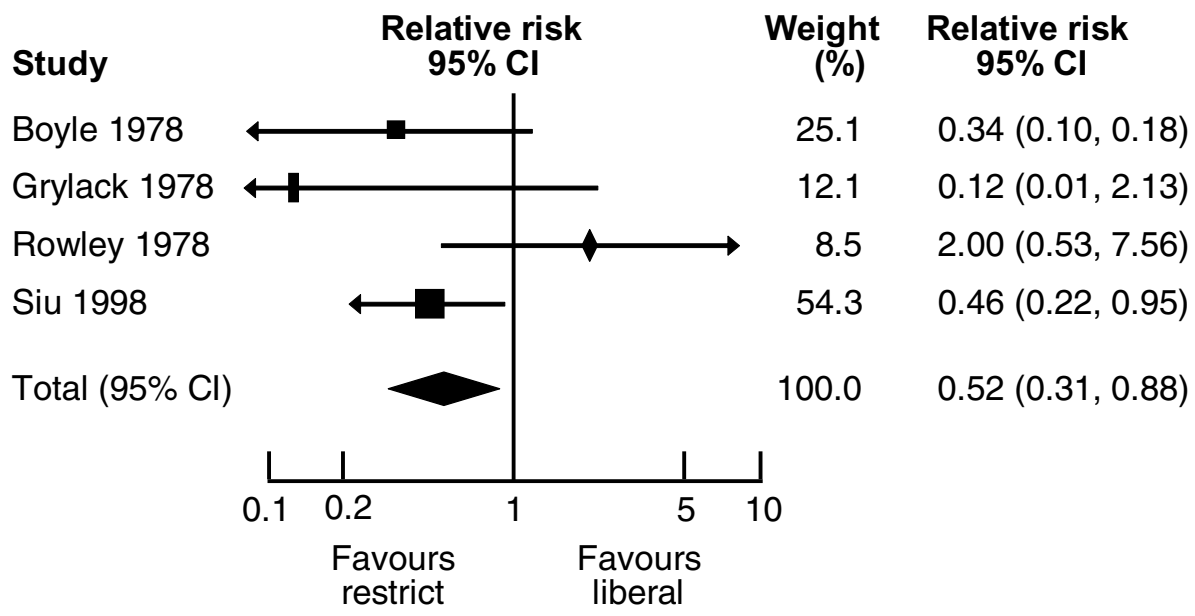

Fig. 3 Enteral antibiotics for preventing necrotizing enterocolitis. Modified from Ref. 55.

Bifidobacteria are the most common organisms recovered from the gastrointestinal tract of breastfed infants, and inhibit colonization with other more pathogenic organisms. Furthermore, bifidobacteria fail to activate key mediators in the inflammatory cascade, enhance immune function of peritoneal macrophages, and do not degrade intestinal mucous glycoproteins. ${ }^{62,63}$ In an animal model of NEC, bifidobacterial supplementation (Bifidobacterium infantis) reduced the incidence of NEC (vs E. coli-treated animals). ${ }^{64}$ In addition, bifidobacteria reduced the plasma concentration of endotoxin and intestinal gene expression of phospholipase $A_{2}$ (an enzyme important in the inflammatory cascade). Similar protective effects of Bifidobacteria have been demonstrated in a quail model of NEC. ${ }^{65}$ In this model, colonization with Bifidobacteria infantis-longum decreased colonization with $C$. butyricum and reduced the produc- tion of butyric acid, a chemical that may be cytotoxic to intestinal epithelium. There are limited data in human newborn infants artificially colonized with bifidobacteria. In a randomized clinical trial to assess potential toxicities, Kitajima et al. administered Bifidobacteria breve to premature infants. ${ }^{66}$ There were no adverse effects attributable to the bacteria, and colonized infants exhibited better weight gain and tolerance of feedings. More recently, Hoyos colonized infants with Lactobacillus acidophilus and B. infantis, and demonstrated a decreased incidence of NEC and NECrelated mortality vs historic controls. ${ }^{67}$ The safety of probiotic supplementation has not been determined in a large prospective trial. Lactobacilli and bifidobacteria are capable of causing infections in humans, especially in immunocompromised hosts. ${ }^{68}$ Therefore, this strategy should not be used until further studies have been completed. 


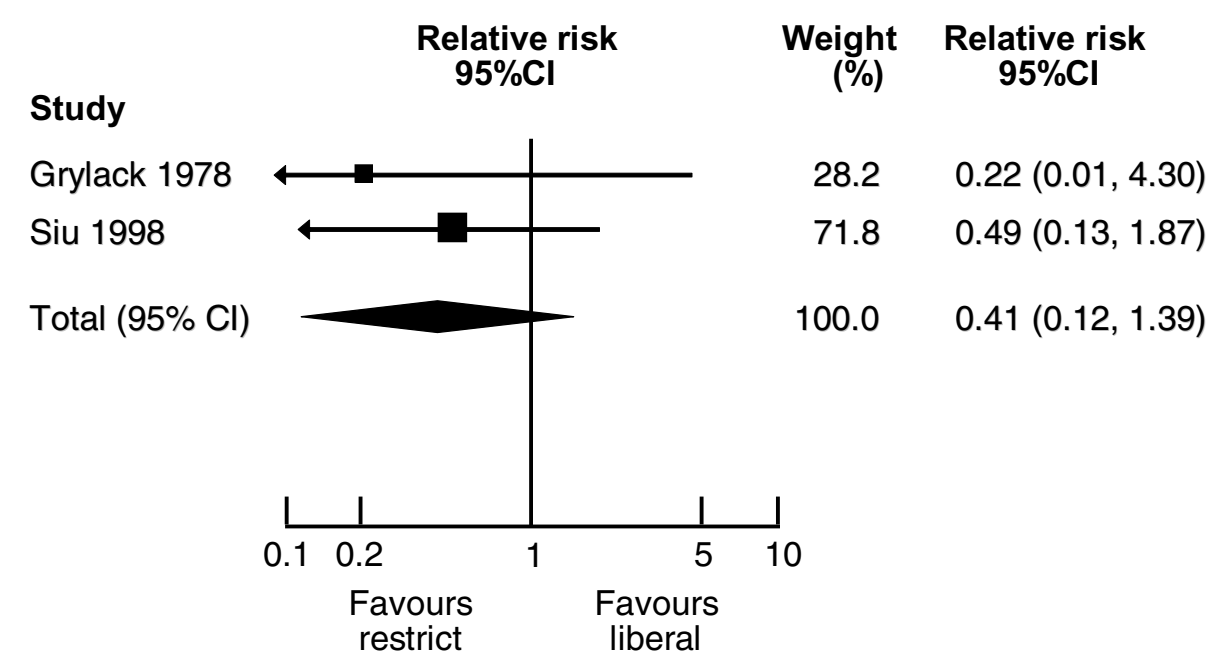

Fig. 4 Enteral antibiotics for preventing necrotizing-enterocolitis-related deaths. Modified from Ref. 55.

There are a number of other retrospective and prospective studies examining prevention strategies for NEC. As part of a secondary analysis of a randomized trial of feeding preterm infants with a formula that was supplemented or not supplemented with egg phospholipids, Carlson et al. demonstrated significantly lower incidences of stages II and III NEC. ${ }^{69}$ Phospholipids contain arachidonic acid, which is a substrate for intestinal vasodilatory and cytoprotective eicosanoids. Furthermore, Caplan et al. have demonstrated that supplementation of formula with polyunsaturated fatty acids reduced the incidence of death and NEC in rat pups, and decreased indices of inflammation. ${ }^{70}$ In a double-blind placebo-controlled trial, Amin et al. investigated the benefit of supplementing the diet of preterm infants with l-arginine $(1.5 \mathrm{mmol} / \mathrm{kg} /$ day). ${ }^{71}$ Arginine is a substrate for production of nitric oxide, an important vasodilator and antiinflammatory mediator. Infants receiving the supplement had a significantly lower incidence of NEC compared with controls. There is a question about the applicability of this study for other NICUs because of the high incidence of NEC (27.3\%) in the control group. Lastly, Carrion and Egan in a prospective double-blind study investigated whether acidification of milk $(0.01-0.02 \mathrm{ml}$ of $1 \mathrm{~N} \mathrm{HCl} / \mathrm{ml}$ of milk) decreased the incidence of NEC. ${ }^{72}$ Infants in the $\mathrm{HCl}$ supplemented group demonstrated a lower gastric $\mathrm{pH}$ and a reduced incidence of NEC (including stage I NEC).

In conclusion, very few strategies have proven efficacious for decreasing the incidence of NEC. Avoidance of preterm birth, use of antenatal steroids (for preterm deliveries), breast-milk feeding, and the use of trophic feedings (for all the other proven benefits) seem reasonable. Use of any other prevention strategy should await the results of further trials.

\section{Practice points}

- Prematurity is the only consistent determinant of NEC; incidence varies inversely with birthweight and gestational age.

- Timing of presentation also varies inversely with gestational age.

- Intestinal ischaemia appears to be the final pathway and not the primary initiator of NEC.

- NEC likely represents an elaborate interaction of factors predisposing to mucosal injury, including the release of vasoconstricting substances and inflammatory mediators.

- A regimen consisting of bowel rest, gastric compression, systemic broad-spectrum antibiotics, and parenteral nutrition is the mainstay of treatment. Intestinal perforation remains the only absolute indication for laparotomy.

- Primary peritoneal drainage may be an alternative to laparotomy in cases of perforated NEC in very-low-birthweight infants.

- Avoidance of preterm birth, judicious use of antenatal steroids in preterm deliveries, breast-milk feedings and trophic feedings may be reasonable strategies in reducing the incidence of NEC.

- Prevention of NEC still remains elusive. 


\section{Research directions}

- A better understanding of the risk factors and the underlying pathway leading to NEC.

- Determination of the role of feeding practices in the pathogenesis of NEC.

- Clarification of the efficacy and safety of probiotic supplementation.

- Development of a prediction model for the risk of NEC.

\section{References}

1. Neu J. Necrotizing enterocolitis: the search for a unifying pathogenic theory leading to prevention. Pediatr Clin North Am 1996;43:409-32.

2. Schmid KO, Quaiser K. Über eine besonders schwer verlaufende Form von Enteritis beim Säugling. Österreichische Zeitschrift für Kinderchirurgie 1953;8:114.

3. Santulli TV, Schullinger JN, Heird WC et al. Acute necrotizing enterocolitis in infancy: a review of 64 cases. Pediatrics 1975;55:376-87.

4. Covert RF, Neu J, Elliott MJ et al. Factors associated with age of onset of necrotizing enterocolitis. Am J Perinatol 1989;6:455-60.

5. Stoll BJ. Epidemiology of necrotizing enterocolitis. Clin Perinatol 1994;21:205-18.

6. Rowe MI, Reblock KK, Kurkchubasche AG et al. Necrotizing enterocolitis in the extremely low birth weight infant. $J$ Pediatr Surg 1994;29:987-90.

7. Chandler JC, Hebra A. Necrotizing enterocolitis in infants with very low birth weight. Semin Pediatr Surg 2000; 9:63-72.

8. Hack M, Wright LL, Shankaran S et al. Very-low-birth-weight outcomes of the National Institute of Child Health and Human Development Neonatal Network, November 1989 to October 1990. Am J Obstet Gynecol 1995;172:457-64.

9. The Vermont-Oxford Trials Network. Very low birth weight outcomes for 1990. Investigators of the VermontOxford Trials Network Database Project. Pediatrics 1993; 91:540-5.

10. Walsh MC, Kliegman RM. Necrotizing enterocolitis: treatment based on staging criteria. Pediatr Clin North Am 1986; 33:179-201.

11. Foglia RP. Necrotizing enterocolitis. Curr Probl Surg 1995; 32:757-823.

12. Kliegman RM, Fanaroff AA. Necrotizing enterocolitis. N Engl J Med 1984;310:1093-103.

13. Uauy RD, Fanaroff AA, Korones SB et al. Necrotizing enterocolitis in very low birth weight infants: biodemographic and clinical correlates. National Institute of Child Health and Human Development Neonatal Research Network. J Pediatr 1991;119:630-8.

14. Ricketts RR. Surgical treatment of necrotizing enterocolitis and the short bowel syndrome. Clin Perinatol 1994; 21:365-87.

15. Molik KA, West KW, Rescorla FJ et al. Portal venous air: the poor prognosis persists. J Pediatr Surg 2001;36:1143-5.

16. Stringer MD, Brereton RJ, Drake DP et al. Recurrent necrotizing enterocolitis. J Pediatr Surg 1993;28:979-81.
17. Bisquera JA, Cooper TR, Berseth CL. Impact of necrotizing enterocolitis on length of stay and hospital charges in very low birth weight infants. Pediatrics 2002;109:423-8.

18. Tobiansky R, Lui K, Roberts $\mathrm{S}$ et al. Neurodevelopmental outcome in very low birthweight infants with necrotizing enterocolitis requiring surgery. J Paediatr Child Health 1995;31:233-6.

19. Sonntag J, Grimmer I, Scholz T et al. Growth and neurodevelopmental outcome of very low birthweight infants with necrotizing enterocolitis. Acta Paediatr 2000; 89:528-32.

20. Stanford A, Upperman JS, Boyle P et al. Long-term follow-up of patients with necrotizing enterocolitis. J Pediatr Surg 2002;37:1048-50.

21. Ledbetter DJ, Juul SE. Necrotizing enterocolitis and hematopoietic cytokines. Clin Perinatol 2000;27:697-716.

22. Kliegman RM. Models of the pathogenesis of necrotizing enterocolitis. J Pediatr 1990;117:2-5.

23. Kosloske AM. Epidemiology of necrotizing enterocolitis. Acta Paediatr 1994;396(Suppl.):2-7.

24. Van Camp JM, Tomaselli V, Coran AG. Bacterial translocation in the neonate. Curr Opin Pediatr 1994; 6:327-33.

25. Israel EJ. Neonatal necrotizing enterocolitis, a disease of the immature intestinal mucosal barrier. Acta Paediatr 1994;396(Suppl.):27-32.

26. Lucas A, Cole TJ. Breast milk and neonatal necrotising enterocolitis. Lancet 1990;336:1519-23.

27. Claud EC, Walker WA. Hypothesis: inappropriate colonization of the premature intestine can cause neonatal necrotizing enterocolitis. Faseb J 2001;15:1398-403.

28. Bennet R, Eriksson M, Nord CE et al. Fecal bacterial microflora of newborn infants during intensive care management and treatment with five antibiotic regimens. Pediatr Infect Dis 1986;5:533-9.

29. Lawrence G, Bates J, Gaul A. Pathogenesis of neonatal necrotising enterocolitis. Lancet 1982;1:137-9.

30. Scheifele DW. Role of bacterial toxins in neonatal necrotizing enterocolitis. J Pediatr 1990;117:S44-6.

31. Hsueh W, Caplan MS, Tan X et al. Necrotizing enterocolitis of the newborn: pathogenetic concepts in perspective. Pediatr Dev Pathol 1998;1:2-16.

32. Edelson MB, Bagwell CE, Rozycki HJ. Circulating pro- and counterinflammatory cytokine levels and severity in necrotizing enterocolitis. Pediatrics 1999;103:766-71.

33. Ng PC, Li K, Wong RP et al. Proinflammatory and antiinflammatory cytokine responses in preterm infants with systemic infections. Arch Dis Child Fetal Neonatal Ed 2003; 88:F209-13.

34. Nanthakumar NN, Fusunyan RD, Sanderson I et al. Inflammation in the developing human intestine: a possible pathophysiologic contribution to necrotizing enterocolitis. Proc Natl Acad Sci U S A 2000;97:6043-8.

35. Ein SH, Marshall DG, Girvan D. Peritoneal drainage under local anesthesia for perforations from necrotizing enterocolitis. J Pediatr Surg 1977;12:963-7.

36. Cheu HW, Sukarochana K, Lloyd DA. Peritoneal drainage for necrotizing enterocolitis. J Pediatr Surg 1988;23:557-61.

37. Takamatsu H, Akiyama H, Ibara S et al. Treatment for necrotizing enterocolitis perforation in the extremely premature infant (weighing less than 1,000 g). J Pediatr Surg 1992;27:741-3.

38. Morgan LJ, Shochat SJ, Hartman GE. Peritoneal drainage as primary management of perforated NEC in the very low birth weight infant. J Pediatr Surg 1994;29:310-4. 
39. Azarow KS, Ein SH, Shandling B et al. Laparotomy or drain for perforated necrotizing enterocolitis: who gets what and why? Pediatr Surg Int 1997;12:137-9.

40. Moss RL, Dimmitt RA, Henry MC et al. A meta-analysis of peritoneal drainage versus laparotomy for perforated necrotizing enterocolitis. J Pediatr Surg 2001;36:1210-3.

41. Moore TC. Successful use of the 'patch, drain, and wait' laparotomy approach to perforated necrotizing enterocolitis: is hypoxia-triggered 'good angiogenesis' involved? Pediatr Surg Int 2000;16:356-63.

42. Patel JC, Tepas JJ III, Huffman SD et al. Neonatal necrotizing enterocolitis: the long-term perspective. Am Surg 1998; 64:575-9.

43. Vennarecci G, Kato T, Misiakos EP et al. Intestinal transplantation for short gut syndrome attributable to necrotizing enterocolitis. Pediatrics 2000;105:E25.

44. Barlow B, Santulli TV, Heird WC. An experimental study of acute neonatal enterocolitis-the importance of breast milk. J Pediatr Surg 1974;9:587-95.

45. Kliegman RM, Pittard WB, Fanaroff AA. Necrotizing enterocolitis in neonates fed human milk. J Pediatr 1979; 95:450-3.

46. Dvorak B, Halpern MD, Holubec $\mathrm{H}$ et al. Maternal milk reduces severity of necrotizing enterocolitis and increases intestinal IL-10 in a neonatal rat model. Pediatr Res 2003; 53:426-33.

47. Goldman AS. Modulation of the gastrointestinal tract of infants by human milk. Interfaces and interactions. An evolutionary perspective. J Nutr 2000;130(2S Suppl.):426S-31S.

48. Caplan MS, MacKendrick W. Inflammatory mediators and intestinal injury. Clin Perinatol 1994;21:235-46.

49. MacKendrick W, Hill N, Hsueh $W$ et al. Increase in plasma platelet-activating factor levels in enterally fed preterm infants. Biol Neonate 1993;64:89-95.

50. McGuire W, Anthony MY. Donor human milk versus formula for preventing necrotising enterocolitis in preterm infants: systematic review. Arch Dis Child Fetal Neonatal Ed 2003; 88:11-4.

51. McGuire W, Anthony MY. Formula milk versus term human milk for feeding preterm or low birth weight infants. Cochrane Database Syst Rev 2001; CD002971.

52. Eibl MM, Wolf HM, Furnkranz $\mathrm{H}$ et al. Prevention of necrotizing enterocolitis in low-birth-weight infants by IgA-lgG feeding. N Engl J Med 1988;319:1-7.

53. Foster J, Cole M. Oral immunoglobulin for preventing necrotizing enterocolitis in preterm and low birth-weight neonates. Cochrane Database Syst Rev 2001; CD001816.

54. Bell EF, Acarregui MJ. Restricted versus liberal water intake for preventing morbidity and mortality in preterm infants. Cochrane Database Syst Rev 2000; CD000503.

55. Bury RG, Tudehope D. Enteral antibiotics for preventing necrotising enterocolitis in low birthweight or preterm infants. Cochrane Database Syst Rev 2000; CD000405.

56. Brown EG, Sweet AY. Preventing necrotizing enterocolitis in neonates. JAMA 1978;240:2452-4.

57. Rayyis SF, Ambalavanan N, Wright L et al. Randomized trial of 'slow' versus 'fast' feed advancements on the incidence of necrotizing enterocolitis in very low birth weight infants. J Pediatr 1999;134:293-7.

58. Kennedy KA, Tyson JE, Chamnanvanikij S. Early versus delayed initiation of progressive enteral feedings for parenterally fed low birth weight or preterm infants. Cochrane Database Syst Rev 2000; CD001970.

59. Kennedy KA, Tyson JE, Chamnanvanikij S. Rapid versus slow rate of advancement of feedings for promoting growth and preventing necrotizing enterocolitis in parenterally fed low-birth-weight infants. Cochrane Database Syst Rev 2000; CD001241.

60. Berseth CL, Bisquera JA, Paje VU. Prolonging small feeding volumes early in life decreases the incidence of necrotizing enterocolitis in very low birth weight infants. Pediatrics 2003;111:529-34.

61. Caplan MS, Jilling T. Neonatal necrotizing enterocolitis: possible role of probiotic supplementation. J Pediatr Gastroenterol Nutr 2000;30(Suppl. 2):18-22.

62. Nicaise $P$, Gleizes $A$, Sandre $C$ et al. Influence of intestinal microflora on murine bone marrow and spleen macrophage precursors. Scand J Immunol 1998;48:585-91.

63. Ruseler-van Embden JG, van Lieshout LM, Gosselink MJ et al. Inability of Lactobacillus casei strain GG, L. acidophilus, and Bifidobacterium bifidum to degrade intestinal mucus glycoproteins. Scand J Gastroenterol 1995;30:675-80.

64. Caplan MS, Miller-Catchpole R, Kaup S et al. Bifidobacterial supplementation reduces the incidence of necrotizing enterocolitis in a neonatal rat model. Gastroenterology 1999;117:577-83.

65. Butel MJ, Roland N, Hibert A et al. Clostridial pathogenicity in experimental necrotising enterocolitis in gnotobiotic quails and protective role of bifidobacteria. J Med Microbiol 1998;47:391-9.

66. Kitajima H, Sumida Y, Tanaka R et al. Early administration of Bifidobacterium breve to preterm infants: randomised controlled trial. Arch Dis Child Fetal Neonatal Ed 1997; 76:101-7.

67. Hoyos $A B$. Reduced incidence of necrotizing enterocolitis associated with enteral administration of Lactobacillus acidophilus and Bifidobacterium infantis to neonates in an intensive care unit. Int J Infect Dis 1999;3:197-202.

68. Borriello SP, Hammes WP, Holzapfel W et al. Safety of probiotics that contain lactobacilli or bifidobacteria. Clin Infect Dis 2003;36:775-80.

69. Carlson SE, Montalto MB, Ponder DL et al. Lower incidence of necrotizing enterocolitis in infants fed a preterm formula with egg phospholipids. Pediatr Res 1998;44:491-8.

70. Caplan MS, Russell T, Xiao Y et al. Effect of polyunsaturated fatty acid (PUFA) supplementation on intestinal inflammation and necrotizing enterocolitis (NEC) in a neonatal rat model. Pediatr Res 2001;49:647-52.

71. Amin HJ, Zamora SA, McMillan DD et al. Arginine supplementation prevents necrotizing enterocolitis in the premature infant. J Pediatr 2002;140:425-31.

72. Carrion V, Egan EA. Prevention of neonatal necrotizing enterocolitis. J Pediatr Gastroenterol Nutr 1990; $11: 317-23$.

Available online at www.sciencedirect.com 